Western University

Scholarship@Western

Human Environments Analysis Lab (HEAL)

2018

Examining How Neighborhood Socioeconomic Status,

Geographic Accessibility, and Informational Accessibility

Influence the Uptake of a Free Population-Level Physical Activity

Intervention for Children

\author{
A. F. Clark \\ Western University, aclark2@uwo.ca \\ Piotr Wilk \\ Western University, pwilk3@uwo.ca \\ Christine A. Mitchell \\ Western University \\ Christine Smith \\ Western University \\ Josh Archer \\ Child \& Youth Netwotrk, London ON
}

See next page for additional authors

Follow this and additional works at: https://ir.lib.uwo.ca/healpub

Citation of this paper:

Clark, A. F.; Wilk, Piotr; Mitchell, Christine A.; Smith, Christine; Archer, Josh; and Gilliland, Jason A., "Examining How Neighborhood Socioeconomic Status, Geographic Accessibility, and Informational Accessibility Influence the Uptake of a Free Population-Level Physical Activity Intervention for Children" (2018). Human Environments Analysis Lab (HEAL). 39.

https://ir.lib.uwo.ca/healpub/39 
Authors

A. F. Clark, Piotr Wilk, Christine A. Mitchell, Christine Smith, Josh Archer, and Jason A. Gilliland 


\title{
Examining How Neighborhood Socioeconomic Status, Geographic Accessibility, and Informational Accessibility Influence the Uptake of a Free Population-Level Physical Activity Intervention for Children
}

American Journal of Health Promotion 2018, Vol. 32(2) 315-324

(C) The Author(s) 2017

Reprints and permission: sagepub.com/journalsPermissions.nav DOI: $10.1177 / 08901$ I71 I77/8433 journals.sagepub.com/home/ahp (S)AGE

\author{
Andrew F. Clark, BA (Hons), MA, PhD ${ }^{1,2}$, Piotr Wilk, BSc (Hons), MSc, PhD ${ }^{1,3,4}$, \\ Christine A. Mitchell, BA (Hons), MA ${ }^{1,2}$, Christine Smith, BSc (Hons) ${ }^{1,2}$, \\ Josh Archer, BA (Hons), MA ${ }^{5}$, and Jason A. Gilliland, BA (Hons), MA, MArch, PhD ${ }^{1,2,3,4,6}$
}

\begin{abstract}
Purpose: To evaluate the uptake of ACT-i-Pass (G5AP), a physical activity (PA) intervention that provides free access to PA opportunities, and to understand the extent to which the intervention provides equitable access to children.

Design: This study evaluates the differences in uptake (ie, enrollment) by comparing postal codes of registrants with the postal codes of all eligible children.

Setting: Children were provided the opportunity to register for the G5AP during the 2014 to 2015 school year in London, Canada.

Participants: The population of grade 5 students in London who registered for the G5AP $(n=1484)$ and did not register $(n=1589)$.

Intervention: The G5AP offered grade 5 students free access to select PA facilities/programs during 2014 to 2015 school year.

Measures: Measures included G5AP registration status, method of recruitment, distance between home and the nearest facility, and neighborhood socioeconomic status.

Analysis: Getis-Ord Gi* and multilevel logistic regression were used to analyze these data.

Results: There were significant differences in the uptake of the G5AP: residing in neighborhoods of high income (odds ratio [OR] $=$ $1.062, P=.029)$ and high proportion of recent immigrants $(O R=1.036, P=.00 \mathrm{I})$ increased the likelihood of $G 5 A P$ registration. Children who were recruited actively were significantly more likely to register for the G5AP $(\mathrm{OR}=2.444, P<.00 \mathrm{I})$.

Conclusion: To increase the uptake of a PA intervention, children need to be actively recruited. Interactive presentations provide children with increased access to information about both the program and its nuances that cannot be communicated as effectively through passive methods.
\end{abstract}

\section{Keywords}

physical activity, intervention, child, community-based, accessibility, uptake

\footnotetext{
${ }^{\prime}$ Human Environments Analysis Laboratory, University of Western Ontario, London, Ontario, Canada

2 Department of Geography, University of Western Ontario, London, Ontario, Canada

${ }^{3}$ Department of Epidemiology \& Biostatistics, University of Western Ontario, London, Ontario, Canada

${ }^{4}$ Department of Paediatrics, University of Western Ontario, London, Ontario, Canada

${ }^{5}$ Healthy Eating-Healthy Physical Activity, Child \& Youth Network, London, Ontario, Canada

${ }^{6}$ School of Health Studies, University of Western Ontario, London, Ontario, Canada
} 


\section{Purpose}

Physical activity (PA) during childhood is associated with a multitude of physical, behavioral, and psychological health benefits. ${ }^{1-6}$ Unfortunately, the majority (91\%) of Canadian children aged 5 to 17 years do not engage in enough PA to obtain these health benefits. ${ }^{7}$ Therefore, it is critical to identify effective interventions that increase children's PA at the population level to ultimately improve the overall health of Canadian children.

Community-based interventions offer a number of advantages as they have the ability to influence a large number of children; however, recent studies have found that participation rates are a major limitation to this type of intervention. ${ }^{8,9}$ Children's participation in PA is influenced by multiple factors at different levels: individual (eg, age, sex, ethnicity, socioeconomic status [SES]), interpersonal (eg, parental and peer support), and community (eg, availability of PA facilities and programs). ${ }^{10-12}$ To develop more effective interventions, greater attention needs to be paid to understanding how different factors influence differences in PA change among different subgroups of children exposed to the same intervention. ${ }^{13}$

Previous studies have largely focused on how effective interventions are at improving the PA levels of children, yet the effectiveness of these interventions have demonstrated limited PA change. ${ }^{9,14,15}$ To gain a more comprehensive understanding of how effective an intervention is at increasing the PA of children, it is important to understand whether an intervention is engaging those in the population who are most in need (eg, children from low-income neighborhoods, ${ }^{11,16-21}$ recent immigrants ${ }^{22-25}$ ). Research exploring the factors that facilitate or hinder the uptake of interventions among different subgroups is critical for improving the effectiveness of interventions and ultimately increasing PA levels among children. ${ }^{26}$ Despite its importance, only a few studies have quantitatively examined factors influencing uptake in detail. ${ }^{27}$

Previous studies that have examined uptake identified a variety of factors that may influence the uptake of PA interventions, including sex, ${ }^{28}$ seasonality, ${ }^{28}$ ethnicity, ${ }^{29}$ social barriers, ${ }^{30}$ and existing PA levels. ${ }^{29,31}$ In addition, mixed results have been reported in studies examining the effects of SES on the uptake of free community-based PA programs: one study found SES to have no impact on uptake, ${ }^{28}$ a second study found children from middle-class families to have the highest uptake rates, ${ }^{29}$ and a third study found low SES children to have the highest uptake rates. ${ }^{32}$ Although the findings regarding the influence of SES are inconclusive, studies of other community-based interventions have found that a lack of transportation hinders children's uptake rate. ${ }^{9,28,33,34}$ Research suggests that even when PA opportunities are abundant, proximity to these locations affects their accessibility, especially for residents from lower SES neighborhoods, ${ }^{21}$ and highlights the need to examine geographic accessibility as a potential factor influencing uptake.

The uptake rates in PA interventions may also be influenced by the amount and quality of information presented to the intervention participants. Recent studies have indicated that children exposed to more information and promotional material about an intervention display greater health behavior change. ${ }^{35,36}$ These findings suggest that access to information about the intervention and the level of exposure can influence whether children engage in PA interventions.

Considering that research shows diverse findings related to the factors affecting intervention uptake, there is a need to further examine the role of these factors in providing equitable access to uptake. Equitable access refers to mitigating health inequalities due to differences in social and economic conditions, whereas equal access refers to everyone receiving equal opportunity regardless of social and economic differences. ${ }^{37,38}$ For instance, community-based PA interventions can provide equal access to a target population; however, the intervention may not be equitable as subgroups of children may experience more difficulties accessing and engaging in the intervention.

To increase PA levels among children, the Child and Youth Network in the city of London, Ontario, Canada, implemented the grade 5 ACT-i-Pass (G5AP) intervention, ${ }^{39}$ inspired by a similar intervention run in Kingston, Ontario. ${ }^{40}$ The G5AP offered all grade 5 children (typically 9-10 years old) plus 1 acquaintance (eg, friend or family member) free access - therefore equal access - to various PA facilities and programs throughout the city, such as drop in programs at 3 YMCA facilities, the Boys and Girls Club, public pools, public arenas, and registered sports classes at municipal recreation centers for an entire school year (September to June). This intervention benefited from strong school board support, well-established partnerships with high-profile service providers, a large variety of activity types offered, the development of creative and age-appropriate marketing strategies, and the elimination of financial barriers in accessing programs. Given these strengths, providing free access was expected to eliminate the financial barrier of accessing recreational programs and facilities for all students in grade 5, regardless of their SES, gender, ethnicity, immigration status, or family structure. Equal access for all prevents potential stigmatization of individuals who may register for the intervention.

The purpose of this study is to understand the extent to which providing equal access to all grade 5 students leads to equitable uptake of the G5AP intervention (ie, registering for the program). We argue that to achieve an equitable uptake in G5AP registration, the intervention must do more than just remove registration fees and provide free accessibility to programs (ie, economic accessibility). Our evaluation therefore considers 2 other dimensions of access that affect equity: geographic accessibility and informational accessibility. As such, we aim to answer 4 related research questions:

1. Does providing every child equal opportunity to register for the G5AP program lead to equal uptake across the city?

2. How is children's uptake of the G5AP associated with the socioeconomic characteristics of the neighborhoods in which they reside? 
3. How is children's uptake of the G5AP associated with the geographic accessibility to the facilities offering free programs?

4. How is children's uptake of the G5AP associated with the level of information children receive about the program at the time of recruitment?

\section{Methods}

\section{Design}

This cross-sectional study evaluated the uptake of a populationbased PA intervention among grade 5 children living in London. Uptake was defined in this study as the proportion of students who register for the G5AP program during their grade 5 school year. A full description of the G5AP intervention study design can be found elsewhere. ${ }^{39}$ The study received research ethics board (REB) approval by The University of Western Ontario (REB\#10394), 4 school boards, and 1 private school in London, Canada.

\section{Sample}

In Spring 2014, all 3651 students (ages 9-10 years) entering grade 5 within 99 schools in London (ie, 93 English-speaking public schools, 5 French-speaking public schools, and 1 private school) were offered a pass that would grant them access to free PA opportunities at selected recreational centers for the duration of their grade 5 school year. Two methods were used to recruit the students to participate in this intervention: active and passive recruitment. Active recruitment involved the research team actively recruiting students using in-class presentations at each school, which included a game to get them active, a description of the project, answers to any questions students had about the program, and distribution of letters to bring home to parents. Passive recruitment involved teachers sending an envelope home to parents with a letter passively informing them about the G5AP intervention. Selection into the active recruitment group was based on randomly selecting 50 schools across London, while stratifying by tertiles of median household income (ie, approximately same number of schools in low-income, middle-income, and high-income groups) to ensure the schools we actively recruited from were representative of the city. The combined recruitment efforts led to 1709 of the 3651 eligible students registering for the G5AP intervention.

The sample used for this study consists of a subset of intervention participants who met the following inclusion criteria: (1) live within London and (2) attend an English-speaking public school. These inclusion criteria were used to remove any children living outside the primary study area (criterion 1) and to allow for linkage to other data sources used in this study (criterion 2). This final sample consisted of 3075 students (1484 registrants and 1591 non-registrants) from the 93 English-speaking public schools.

\section{Data}

This study used 3 key data sources: G5AP registration records, a school bus eligibility geodatabase, and the 2011 Census of Canada. The G5AP registration process provided a record of every student who registered for the G5AP, including their home postal codes. With REB approval, personally identifiable information was collected through the registration process for the purposes of distributing passes to registered students; however, none of that information was used in this study. The school bus geodatabase included postal codes for every grade 5 student attending one of the 93 English-speaking public schools within London $(\mathrm{N}=3075)$ but included no personal information on individual students (eg, name, gender). The 2011 Census of Canada provided measures of SES at the census dissemination area (DA) level. Dissemination areas are often used as neighborhood proxies as they are fairly uniform in terms of population size (targeted to include 400-700 persons) and are the smallest geographic units for which socioeconomic variables are released by Statistics Canada. ${ }^{41}$

\section{Measures}

Dependent variable. The dependent variable in this study was uptake status, defined as whether a grade 5 student registers for the 2014 to 2015 G5AP intervention (1) or not (0). This variable was calculated by combining the school bus eligibility database (all children) with the G5AP registration database (registered children) by postal code. Postal codes from the school bus database with a matching G5AP registration were given the value of 1 and postal codes without a matching registration were given a value of 0 .

Independent variables. Neighborhood socioeconomic characteristics were measured using data from the 2011 Census of Canada. Area-level measures of SES for each child's neighborhood (DA) included median household income ( $\$ C D N)$, proportion of families headed by lone parent (\%), percentage of the population who immigrated to Canada between 2006 and $2011(\%)$, and percentage of the adult population without a high school diploma (\%). These continuous variables representing neighborhood SES were used to better understand if there is inequity in G5AP uptake across the city, specifically among those living in neighborhoods with low SES.

Geographic accessibility was defined as the ease that locations of opportunities, such as for PA, shopping, and food, can be reached from a given location. ${ }^{42-44}$ It is operationalized in this study as a proximity to the nearest recreation center, which is measured as the distance along the road network in kilometers between each student's postal code (home) and the closest G5AP facility (ie, city pools and recreation centers, YMCA of Western Ontario, and Boys and Girls Club of London). ${ }^{17,45,46}$ This variable was computed in a geographic information system using the Network Analyst tool in ArcGIS $10.3{ }^{47}$ Using postal codes as proxies for home addresses maintains subject anonymity but does add some spatial inaccuracy 
in the measure. Nevertheless, previous research has shown that the positional errors introduced by using postal codes in urban areas such as London are marginal and acceptable in public health research. ${ }^{41}$

Informational accessibility was defined in this study as receiving the full project details and better understanding how to enroll and use the G5AP. It was measured as a binary variable indicating the method by which information about the G5AP was provided to the students in each school: active recruitment (1) and passive recruitment (0). Active recruitment increased the informational accessibility of the students to the G5AP, as the intricacies of the project were explained (eg, benefits of PA, how to register, how to use the pass, free transportation provided by a partner, program was $100 \%$ free).

\section{Analysis}

This article used two methods of statistical analysis to reveal the individual effects of neighborhood SES, geographic accessibility, and informational accessibility on uptake of the G5AP intervention: Getis-Ord Gi* hot-spot analysis and multilevel binary logit analysis. The cutoff for assessment of statistical significance for all analyses was based on $P$ values less than .05 .

The Getis-Ord Gi* hot-spot statistic (research question 1) is a measure of spatial autocorrelation used to detect spatial clustering of high and low recruitment rates for the G5AP among spatially delineated polygons. ${ }^{48}$ The analysis for this study was conducted in ArcGIS 10.3 by comparing the uptake rates of each DA with the values in the surrounding DAs to identify high or low values as compared to the overall average uptake rates. The following equation was used to measure Getis-Ord $\mathrm{Gi}^{*}$ statistic $^{49}$ :

$$
G_{i}^{*}=\frac{\sum_{j=1}^{n} w_{i j} x_{j}-\bar{X} \sum_{j=1}^{n} w_{i j}}{S \sqrt{\frac{n \sum_{j=1}^{n} w_{i j}^{2}-\left(\sum_{j=1}^{n} w_{i j}\right)}{n-1}}},
$$

where $x_{j}$ is the value of the $j$ th point, $w_{i j}$ is the spatial weight between $i$ and $j, n$ is equal to the total number of features, and

$$
\begin{gathered}
\bar{X}=\frac{\sum_{j=1}^{n} x_{j}}{n} . \\
S=\sqrt{\frac{\sum_{j=1}^{n} x_{j}^{2}}{n}-(\bar{X})^{2} .}
\end{gathered}
$$

The $G_{i}^{*}$ statistic was interpreted as a $z$-score and it provided evidence on the extent to which uptake rates at the DA level were clustered around high and low values (hot and cold spots). The results of the analysis are shown on a map to allow for interpretation.
A multilevel binary logistic regression analysis was used to address research questions 2,3 , and 4 . The models estimated in this study were based on the following generic model:

$$
W_{i, j}=\beta_{0}+\beta_{1 j} X_{i j}+\mu_{0 j},
$$

where $i$ represents the $i$ th child, $j$ represents the $j$ th DA, $W_{i j}$ represents the uptake status of the location $i$ th child from a $j$ th DA, $\beta_{0}$ refers to the intercept of the dependent variables in the model, $\beta_{1 \mathrm{j}}$ is the intercept for a child-level independent variable, $X_{i j}$ represents a value for child-level independent variables, and $\mu_{0 j}$ is the unexplained random intercept variance or the between DA variance. Model 1, the null model, was used to assess the amount of variance in the outcome variable across DAs. Sets of independent variables were then added independently into the model to assess how each set of variables impact the between DA variance. Specifically, model 2 included measures of neighborhood SES (research question 2), model 3 included a measure of geographic accessibility (research question 3), and model 4 included a measure of informational accessibility (research question 4). As the recruitment methods used in the G5AP intervention can significantly alter uptake, 2 additional models attempted to tease out how measures of neighborhood SES and geographic accessibility impact uptake among passively recruited students (model 5) or actively recruited students (model 6). The multilevel models were estimated with STATA 12.0 SE ${ }^{50}$ using adaptive Gaussian quadrature method. ${ }^{51}$

\section{Results}

A total of 1484 (48\%) of 3075 eligible children from 93 publicly funded English elementary schools in London registered for the G5AP intervention. The locations of G5AP intervention and uptake rate for participants by DA throughout London are illustrated in Figure 1. The lightest shade on the map represents the areas of lowest uptake rate and the shades become more saturated as uptake rate increases. The results show that the uptake rates varied throughout the city, suggesting that the G5AP uptake was not equal across London.

To better understand where uptake rates have a statistically significant geographic clustering throughout the city, a hot-spot analysis was conducted using Getis-Ord Gi*. The results displayed in Figure 2 reveal that there was significant clustering of high and low uptake rates. Significantly low uptake rates (shown in blue) stretched from the core to the northeast part of the city. This area is characterized by multiple recreation facilities (as seen in Figure 1) and low SES, with a few higher SES areas scattered throughout (as seen in Figure 3). There were clusters of significantly high uptake rates in different areas of the city, with the largest area being in the northwest. This area has neighborhoods with mixed SES status, with some of the highest and lowest SES neighborhoods in the city located within this high uptake cluster. In contrast, the clustering of high uptake rates found in the southwest and southeast areas was both in middle to low SES neighborhoods. These results imply that uptake rates were not equal across London. 




Figure I. Uptake rate for the grade 5 ACT-i-Pass program by dissemination area in London, Canada.

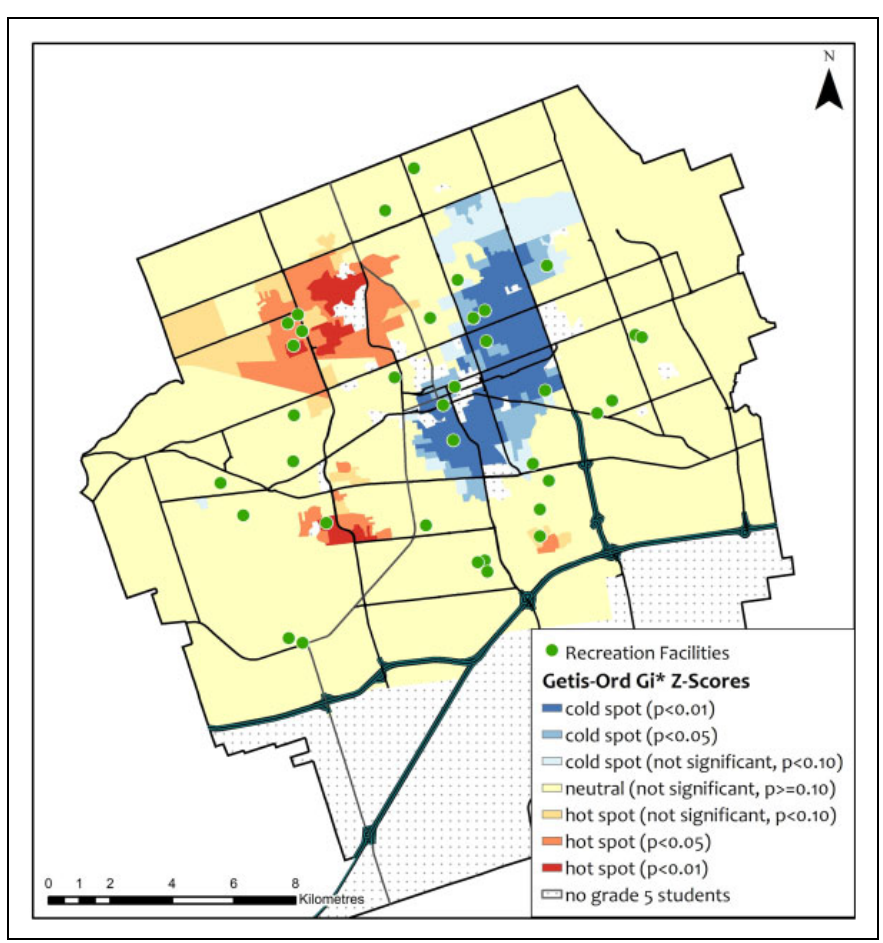

Figure 2. Results of the Getis-Ord Gi* hot- and cold-spot analysis of ACT-i-Pass uptake rates in London, Canada.

The objective of the logistic regression analysis was to investigate whether lack of equal accessibility in the uptake rates can be attributed to neighborhood SES, geographic accessibility, and informational accessibility. Results of the

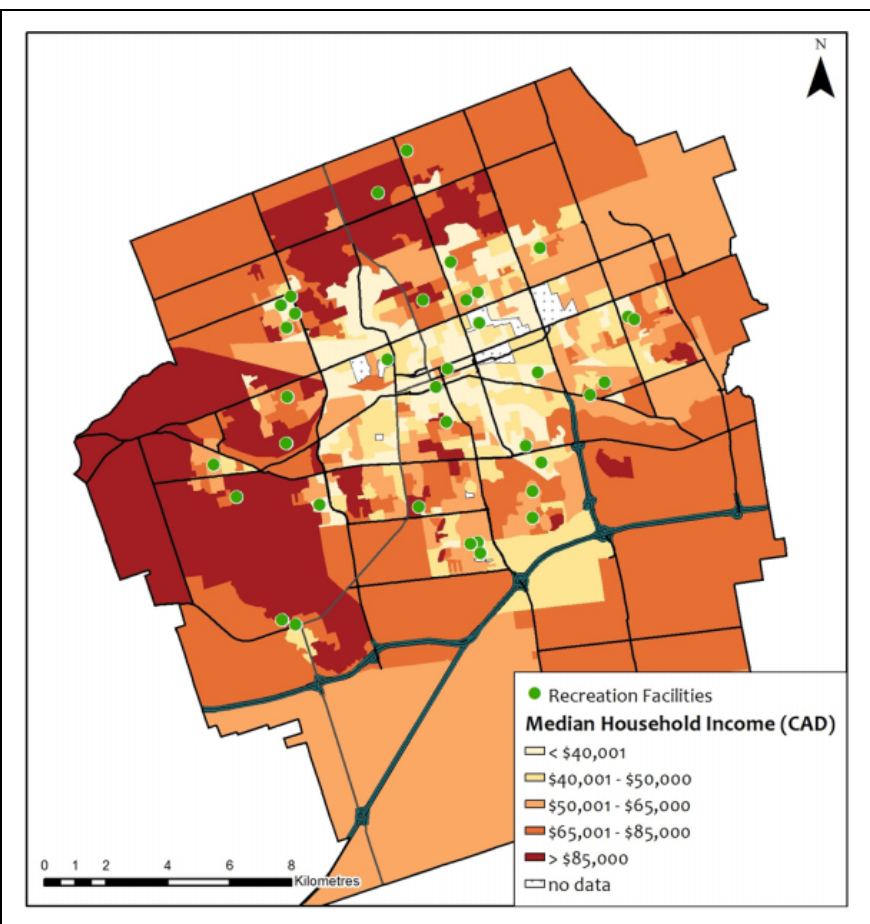

Figure 3. Median household income in Canadian dollar (20II) by census dissemination area in London, Canada.

logistic regression analyses are found in Table 1 . The null model (model 1) shows a variance of 0.384 in the outcome variable. When adding socioeconomic characteristics to the null model (model 2), the variance decreased by $8.1 \%$ to 0.352 , with neighborhood median household income (odds ratio $[\mathrm{OR}]=1.062, P=.029)$ and percentage of recent immigrants $(\mathrm{OR}=1.036, P=.001)$ having a statistically significant positive effect on registering for the G5AP. When accounting for the geographic accessibility of the nearest recreation facility (model 3), explained variance only decreased to 0.383 compared to the null model. Considering the method in which the G5AP was delivered to the students (models 4), active recruitment was significantly related to increased uptake compared to passive recruitment $(\mathrm{OR}=$ $2.444, P<.001)$. Informational accessibility accounted for $20.3 \%$ of variance found in the null model.

As informational accessibility was strongly related to G5AP uptake, we undertook additional analyses of how uptake is related to neighborhood SES and geographic accessibility for students who were recruited passively (model 5) and those recruited actively (model 6). The results from model 5 suggest that an increase in the proportion of lone parenthood (OR $=1.024, P=.028)$ in a neighborhood had a statistically significant positive effect on registering for the G5AP. In contrast, the results from model 6 suggest that, among students actively recruited to the intervention, the only neighborhood characteristic related to an increase in registration was the percentage of recent immigrants living within a neighborhood (OR = $1.038, P=0.005)$. 
Table I. Results of Multilevel Binary Logit Models Examining How Uptake Is Influenced by Neighborhood Socioeconomic Status, Geographic Accessibility, and Informational Accessibility.

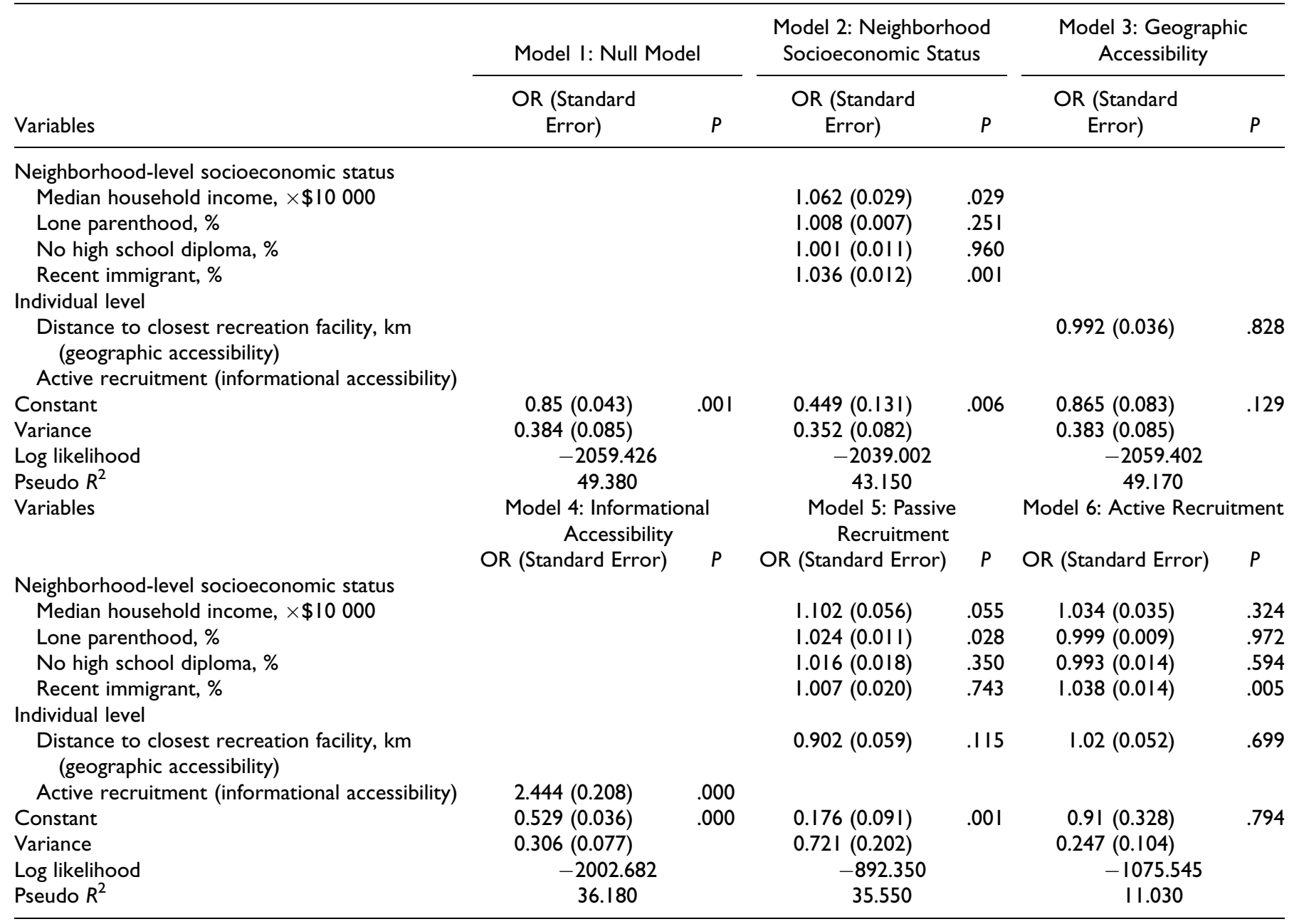

\section{Discussion}

Uptake of the G5AP intervention appears to be unequal and inequitable. The populations that this program was supposed to benefit the most were not necessarily accessing the program. This finding was immediately reflected in the overall registration uptake rate of the program among grade 5 students (48\%). Despite reaching almost half of the grade 5 students, geographic hot spot analysis shows that there were geographic areas of low and high uptake throughout the city. In fact, areas where low uptake was present coincides with areas that have populations with lower incomes, suggesting that it is important to understand the complexity of this relationship through modeling.

The results of this modeling, however, are mixed. The findings show that those living in neighborhoods with a high proportion of recent immigrants (in the total sample and in the subsample of children actively recruited) and neighborhoods with a higher proportion of families with lone parents (in the subsample of those passively recruited) had a higher likelihood of registering for the G5AP intervention. Despite these positive trends, a decrease in median household income was found to decrease the likelihood of registering for the intervention (in the total sample). In other words, the higher need households that would benefit the most from an intervention like the G5AP (which reduces financial barriers to accessing recreation) were less likely to register for the G5AP. Accounting for informational accessibility, the results indicate that the method of providing information to the students appears to reduce inequity in uptake and is a more important factor than neighborhood socioeconomic characteristics or geographic accessibility. Children who received the information about the G5AP passively were less likely to register.

There is also a great deal of unexplained variance in this analysis, which suggests that eliminating the cost of participating in PA alone did not account for all of the barriers that prevented students from registering for the program. Other studies have shown that a lack of social support from parents and peers is a well-established barrier to children's PA. ${ }^{52-55}$ Other barriers include inadequate skills or feeling incompetent, ${ }^{52}$ as well as additional costs associated with some forms of PA (eg, proper equipment and travel). ${ }^{56}$ Finally, parents 
have been found to perceive the school as the main provider for children's PA and report challenges in motivating children to be active. ${ }^{57}$ Although the G5AP removed the financial cost of registering or paying to participate in PA programs, it is evident that to get more equal and equitable uptake in a PA intervention requires further investigation (including interviews and/or focus groups) to develop a deeper understanding of the underlying causes of why certain children and their parents were not taking advantage of free PA programs.

Results from this study provide some key lessons to consider when developing free or low-cost community-based PA interventions for children. It is important to find resources that actively promote the intervention through interactive and engaging methods to increase the uptake and equity of the program. By actively providing children with information about the G5AP and getting them excited about the program during the active recruitment process, the promotion team may have been able to overcome the socioeconomic barriers that were experienced by those who received the information passively. For instance, the team was able to make sure the students understood what the program was about and provided greater detail on important features of the program, such as free transportation offered by one of the service providers. If active recruitment is not possible, it is important to identify strategies that can help to ensure every student in the target population receives the same information in the same manner to decrease inequity, recognizing that specialized strategies may need to be developed and employed to reach certain high-need populations. This can be done by creating an information protocol, promotional videos, and a frequently asked questions sheet that teachers can use to (1) educate their students about the program, (2) answer any questions they have, and (3) help students become excited about an intervention that can improve their PA. Previous studies utilizing a marketing approach have found significant improvements in PA behavior. Other interventions that provided a range of promotional materials, ${ }^{58}$ had a high level of implementation and exposure, ${ }^{35,36}$ and included a parental information component displayed positive results. ${ }^{59}$

If active recruitment in schools is not financially feasible, strategies that aim to increase the general public's awareness of the program in the larger community setting could also help decrease the informational accessibility gap of the program. For example, a comprehensive marketing campaign that runs the length of the active registration process with tailored messaging directed toward caregivers could positively influence uptake rates. It is important to note that locations for marketing the program can be chosen using existing research ${ }^{60}$ and should be geared toward the specific audience of children and caregivers, recognizing that the impact of campaigns would extend beyond the target audience.

Although the findings were not statistically significant, the negative relationship between uptake and distance also suggests that if the resources to actively promote the program do not exist, it may still be important to find ways to minimize the impact of travel distance between a child's home and facilities offering programs. This may be done by increasing the number of facilities and/or service providers involved in the program or by providing free public transportation as part of the program. For instance, a community-based hip-hop program provided free transportation assistance (ie, service provider van and bus tickets) for the duration of the PA intervention; however, once the intervention ended, many of the youth receiving transportation assistance did not return. ${ }^{34,61}$ This highlights the need to develop sustainable transportation services that will foster children's participation in PA. One of the service providers involved in the G5AP already provides free transportation to children to attend their drop-in programs. Although this information was provided in the information packages sent home to all parents, the promotion team was able to highlight this as a service available to those who received active recruitment, further increasing their knowledge and accessibility to the G5AP intervention.

While this study provides evidence on the extent to which neighborhood SES, geographic accessibility, and informational accessibility impact the uptake of the G5AP, there are some study limitations that may have contributed to the mixed results. The most significant limitation is that surveys were not available for students who chose not to register for the G5AP intervention, and therefore, no individual-level measures of household SES could be used in the analyses. As a proxy for individual-level SES, our analyses adopted a commonly used strategy by incorporating neighborhood-level measures of SES based on DA data from the Canadian census. ${ }^{4,62}$ Although census DAs in London represent relatively small and homogeneous areas, we were careful to discuss these data in terms of the neighborhoods in which students reside, rather than using it to make inferences about individual students. By understanding the neighborhood-level SES of registrants and nonregistrants, future program delivery can work to more efficiently target populations for neighborhood-based interventions.

Another limitation is that we did not have access to data on nonregistrant students from the 6 French-speaking schools; however, as a large proportion of students at these schools live outside the city limits, this subgroup represented less than $3 \%$ of the total population of eligible students for the G5AP.

There is also a need to have a more thorough understanding of how to improve the G5AP intervention. Many of the potential gaps can be identified and solutions can be developed through focus groups conducted with school board officials, service providers, parents, and children. Talking to school board officials may provide evidence as to what school-level barriers exist that need to be overcome, to effectively use passive recruitment methods. Speaking with service providers may provide a better understanding of the front-line staff's knowledge of the program and therefore their ability to promote the program outside of the school system. Interviewing parents, especially those in low SES neighborhoods, may help identify the barriers they face when choosing to register their child for the program. Finally, conducting focus groups with children may provide evidence as to what would make the program more attractive and interesting to them. The final limitation of this study is that uptake, defined as registration, does not 


\section{SO WHAT?}

\section{What is already known on this topic?}

The majority of children do not engage in enough physical activity to achieve the associated physical, behavioral, and psychological health benefits. Previous research has identified cost as a key barrier to children's physical activity participation. Community-based interventions to increase children's physical activity levels have the ability to reach large populations; however, uptake rates are a major limitation of this type of intervention.

\section{What does this article add?}

Through a novel application of geographic hot-spot analysis, this study shows how offering an entire population of children free access to physical activity opportunities did not result in equal uptake throughout the community. Multilevel logistic regression analysis revealed that the likelihood of registering for the free program was higher among children who were actively recruited and came from neighborhoods with high incomes or a higher proportion of recent immigrants.

\section{What are the implications for health promotion practice or research?}

Active recruitment for physical activity interventions increased levels of uptake, especially for children from low socioeconomic status neighborhoods. If active recruitment is not possible, programs must find ways to increase knowledge about the program among target populations.

equate to utilization. Future work needs to examine how the utilization of the G5AP varies by SES, baseline PA levels, parental support, informational accessibility, and geographic accessibility. This may provide evidence as to whether the G5AP is being used by those who need it most, such as girls, children from low SES households, and children who have low levels of PA at baseline.

\section{Authors' Note}

The design, funding, and implementation of the ACT-i-Pass program was undertaken by London's Child and Youth Network (CYN; http:// londoncyn.ca). Physical activity programs were provided by the Boys and Girls Club of London, the YMCA of Western Ontario, and the City of London. The evaluation of the ACT-i-Pass program was conducted by researchers affiliated with the Human Environments Analysis Laboratory (http://theheal.ca) at the University of Western Ontario.

\section{Acknowledgments}

The authors would like to thank our community partners and funders for their support of the ACT-i-Pass program.

\section{Declaration of Conflicting Interests}

The author(s) declared no potential conflicts of interest with respect to the research, authorship, and/or publication of this article.

\section{Funding}

The author(s) disclosed receipt of the following financial support for the research, authorship, and/or publication of this article: Canadian Cancer Society Research Institute, 703083, Children's Health Research Institute and Children's Health Foundation, Government of Canada, Canadian Institutes of Health Research, Institute of Population and Public Health, 322703, 327369. The Ontario Sport and Recreation Communities Fund provided funding to the CYN to help implement the program.

\section{References}

1. Baranowski T, Bouchard C, Bar-Or O, et al. Assessment, prevalence, and cardiovascular benefits of physical activity and fitness in youth. Med Sci Sports Exerc. 1992;24(suppl 6):S237-S247.

2. Janssen I, LeBlanc AG. Systematic review of the health benefits of physical activity and fitness in school-aged children and youth. Int J Behav Nutr Phys Act. 2010;7(1):40.

3. Reiner M, Niermann C, Jekauc D, Woll A. Long-term health benefits of physical activity - a systematic review of longitudinal studies. BMC Public Health. 2013;13(1):813.

4. Shaibi GQ, Faulkner MS, Weigensberg MJ, Fritschi C, Goran MI. Cardiorespiratory fitness and physical activity in youth with type 2 diabetes. Pediatr Diabetes. 2008;9(5):460-463.

5. Trudeau F, Shephard RJ. Relationships of physical activity to brain health and the academic performance of schoolchildren. Am J Lifestyle Med. 2010;4(2):138-150.

6. Williams J, Wake M, Hesketh K, Maher E, Waters E. Healthrelated quality of life of overweight and obese children. JAMA. 2005;293(1):70-76.

7. ParticipACTION. Are Canadian kids too tired to move? The 2016 ParticipACTION Report Card on Physical Activity for Children and Youth. Toronto: ParticipACTION; 2016.

8. Salmon J, Booth ML, Phongsavan P, Murphy N, Timperio A. Promoting physical activity participation among children and adolescents. Epidemiol Rev. 2007;29(1):144-159.

9. Jago R, Baranowski T. Non-curricular approaches for increasing physical activity in youth: a review. Prev Med (Baltim). 2004; 39(1):157-163.

10. Sallis JF, Prochaska JJ, Taylor WC. A review of correlates of physical activity of children and adolescents. Med Sci Sports Exerc. 2000;32(5):963-975.

11. Van Der Horst K, Paw MJCA, Twisk JWR, Van Mechelen W. A brief review on correlates of physical activity and sedentariness in youth. Med Sci Sports Exerc. 2007;39(8):1241-1250.

12. Trost SG, Loprinzi PD. Parental influences on physical activity behavior in children and adolescents: a brief review. Am J Lifestyle Med. 2011;5(2):171-181.

13. Perry CK, Garside H, Morones S, Hayman LL. Physical activity interventions for adolescents: an ecological perspective. J Prim Prev. 2012;33(2-3):111-135.

14. Hillier-Brown FC, Bambra CL, Cairns JM, Kasim A, Moore HJ, Summerbell CD. A systematic review of the effectiveness of 
individual, community and societal level interventions at reducing socioeconomic inequalities in obesity amongst children. $B M C$ Public Health. 2014;14(1):834.

15. van Sluijs EMF, Kriemler S, McMinn AM. The effect of community and family interventions on young people's physical activity levels: a review of reviews and updated systematic review. $\mathrm{Br} J$ Sports Med. 2011;45(11):914-922.

16. O’Loughlin J, Paradis G, Kishchuk N, Barnett T, Renaud L. Prevalence and correlates of physical activity behaviors among elementary schoolchildren in multiethnic, low income, inner-city neighborhoods in Montreal, Canada. Ann Epidemiol. 1999;9(7): 397-407.

17. Tucker P, Irwin JD, Gilliland J, He M, Larsen K, Hess P. Environmental influences on physical activity levels in youth. Health Place. 2009;15(1):357-363.

18. Stalsberg R, Pedersen AV. Effects of socioeconomic status on the physical activity in adolescents: a systematic review of the evidence. Scand J Med Sci Sports. 2010;20(3):368-383.

19. Lasheras L, Aznar S, Merino B, López EG. Factors associated with physical activity among Spanish youth through the national health survey. Prev Med (Baltim). 2001;32(6):455-464.

20. Tandon PS, Zhou C, Sallis JF, Cain KL, Frank LD, Saelens BE. Home environment relationships with children's physical activity, sedentary time, and screen time by socioeconomic status. Int $J$ Behav Nutr Phys Act. 2012;9(1):88.

21. Estabrooks PA, Lee RE, Gyurcsik NC. Resources for physical activity participation: does availability and accessibility differ by neighborhood socioeconomic status? Ann Behav Med. 2003; 25(2):100-104.

22. Tremblay MS, Bryan SN, Pérez CE, Ardern CI, Katzmarzyk PT. Physical activity and immigrant status: evidence from the Canadian Community Health Survey. Can J public Health. 97(4): 277-282.

23. Singh GK, Yu SM, Siahpush M, Kogan MD. High levels of physical inactivity and sedentary behaviors among US immigrant children and adolescents. Arch Pediatr Adolesc Med. 2008;162(8): 756-763.

24. Dunn JR, Dyck I. Social determinants of health in Canada's immigrant population: results from the National Population Health Survey. Soc Sci Med. 2000;51(11):1573-1593.

25. Bruce Newbold K, Danforth J. Health status and Canada's immigrant population. Soc Sci Med. 2003;57(10):1981-1995.

26. Glasgow RE, Klesges LM, Dzewaltowski DA, Bull SS, Estabrooks $\mathrm{P}$. The future of health behavior change research: what is needed to improve translation of research into health promotion practice? Ann Behav Med. 2004;27(1):3-12.

27. Durlak JA, DuPre EP. Implementation matters: a review of research on the influence of implementation on program outcomes and the factors affecting implementation. Am J Community Psychol. 2008;41(3-4):327-350.

28. Audrey S, Wheeler BW, Mills J, Ben-Shlomo Y. Health promotion and the social gradient: the free swimming initiative for children and young people in Bristol. Public Health. 2012; 126(11):976-981.

29. Koorts H, Gillison F. Mixed method evaluation of a communitybased physical activity program using the RE-AIM framework: practical application in a real-world setting. BMC Public Health. 2015;15(1):1102.

30. Pate RR, Trost SG, Mullis R, Sallis JF, Wechsler H, Brown DR. Community interventions to promote proper nutrition and physical activity among youth. Prev Med (Baltim). 2000;31(2): S138-S149.

31. De Meij JSB, Chinapaw MJM, Kremers SPJ, Van der wal MF, Jurg ME, Van Mechelen W. Promoting physical activity in children: the stepwise development of the primary school-based JUMP-in intervention applying the RE-AIM evaluation framework. Br J Sports Med. 2010;44(12):879-887.

32. Nickelson J, Alfonso ML, McDermott RJ, Bumpus EC, Bryant CA, Baldwin JA. Characteristics of "tween" participants and nonparticipants in the VERBTM summer scorecard physical activity promotion program. Health Educ Res. 2011;26(2):225-238.

33. Casey R, Oppert JM, Weber C, et al. Determinants of childhood obesity: what can we learn from built environment studies? Food Qual Prefer. 2014;31(1):164-172.

34. Beaulac J, Olavarria M, Kristjansson E. A community-based hiphop dance program for youth in a disadvantaged community in Ottawa: implementation findings. Health Promot Pract. 2010; 11(suppl 3):61S-69S.

35. Schneider M, DeBar L, Calingo A, et al. The effect of a communications campaign on middle school students' nutrition and physical activity: results of the HEALTHY study. $J$ Health Commun. 2013;18(6):649-667.

36. Saunders RP, Pate RR, Dowda M, Ward DS, Epping JN, Dishman RK. Assessing sustainability of Lifestyle Education for Activity Program (LEAP). Health Educ Res. 2012;27(2):319-330.

37. Chang WC. The meaning and goals of equity in health. J Epidemiol Community Health. 2002;56(7):488-491.

38. Canadian Medical Association. Health Equity and the Social Determinants of Health. Ottawa, ON: Advocacy Physician Health Wellness. 2016.

39. Gilliland JA, Clark AF, Tucker P, Prapavessis H, Avison W, Wilk P. The ACT-i-pass study protocol: how does free access to recreation opportunities impact children's physical activity levels? BMC Public Health. 2015;15(1):1286.

40. Connelly G. Family Influence on Children's Physical Activity and their Use of Kingston Gets Active's Grade 5 Community Physical Activity Pass. Kingston, Ontario: Queen's University, School of Kinesiology and Health Studies; 2010.

41. Healy MA, Gilliland JA. Quantifying the magnitude of environmental exposure misclassification when using imprecise address proxies in public health research. Spat Spatiotemporal Epidemiol. 2012;3(1):55-67.

42. Bureau of Transportation. 1997 Transportation Statistics Annual Report BTS97-2-01. Washington, DC: Bureau of Transportation; 1997.

43. Engwicht D. Reclaiming Our Cities and Towns: Better Living With Less Traffic. Gabriola Island, British Columbia: New Catalyst Books; 2007.

44. Hansen WG. How accessibility shapes land use. J Am Inst Plann. 1959;25(2):73-76.

45. Mitchell C, Clark A, Gilliland J. Built environment influences of children's physical activity: examining differences by 
neighbourhood size and sex. Int $J$ Environ Res Public Health. 2016;13(1):130.

46. Geurs KT, Krizek KJ, Reggiani A. Accessibility Analysis and Transport Planning: Challenges for Europe and North America. Northampton, Massachusetts: Edward Elgar; 2012.

47. Environmental Systems Research Institute. ArcGIS Desktop: Release 10. Redlands, CA: Environmental Systems Research Institute; 2011.

48. Anselin L. Local Indicators of Spatial Association-LISA. Geogr Anal. 2010;27(2):93-115.

49. Environmental Systems Research Institute. How Hot Spot Analysis: Getis-Ord Gi* (Spatial Statistics) Works. ArcGIS 93 Help File. Redlands, CA; 2005.

50. StataCorp. Stata Statistical Software: Release 15. College Station, TX: StataCorp LLC; 2017.

51. Pinheiro JC, Chao EC. Efficient Laplacian and adaptive Gaussian quadrature algorithms for multilevel generalized linear mixed models. J Comput Graph Stat. 2006;15(1):58-81.

52. Bélanger M, Casey M, Cormier M, et al. Maintenance and decline of physical activity during adolescence: insights from a qualitative study. Int J Behav Nutr Phys Act. 2011;8(1):117.

53. Duncan SC, Duncan TE, Strycker LA. Sources and types of social support in youth physical activity. Heal Psychol. 2005;24(1): 3-10.

54. Beets MW, Vogel R, Forlaw L, Pitetti KH, Cardinal BJ. Social support and youth physical activity: the role of provider and type. Am J Health Behav. 2006;30(3):278-289.
55. Pate RR, Saunders RP, Ward DS, Felton G, Trost SG, Dowda M. Evaluation of a community-based intervention to promote physical activity in youth: lessons from active winners. Am J Health Promot. 17(3):171-182.

56. Dwyer JJM, Allison KR, Goldenberg ER, Fein AJ, Yoshida KK, Boutilier MA. Adolescent girls' perceived barriers to participation in physical activity. Adolescence. 2006;41(161): 75-89.

57. Trigwell J, Murphy RC, Cable NT, Stratton G, Watson PM. Parental views of children's physical activity: a qualitative study with parents from multi-ethnic backgrounds living in England. BMC Public Health. 2015;15(1):1005.

58. Huhman ME, Potter LD, Nolin MJ, et al. The influence of the VERB campaign on children's physical activity in 2002 to 2006. Am J Public Health. 2010;100(4):638-645.

59. Price SM, Huhman M, Potter LD. Influencing the parents of children aged 9-13 years. Am J Prev Med. 2008;34(6):S267-S274.

60. Stewart TC, Polgar D, Gilliland J, et al. Shaken baby syndrome and a triple-dose strategy for its prevention. J Trauma. 2011; 71(6):1801-1807.

61. Beaulac J, Kristjansson E, Calhoun M. "Bigger than hip-hop?" Impact of a community-based physical activity program on youth living in a disadvantaged neighborhood in Canada. $J$ Youth Stud. 2011;14(8):961-974.

62. Larsen K, Gilliland J, Hess PM. Route-based analysis to capture the environmental influences on a child's mode of travel between home and school. Ann Assoc Am Geogr. 2012;102(6):1348-1365. 